\title{
Analysis of Photovoltaic Poverty Alleviation Policy in Yuexi, Anhui Province
}

\author{
Yuejie Zhang \\ School of Economics, Renmin University of China, Beijing 100872, China; \\ impapaya@163.com
}

Keywords: Targeted poverty alleviation, photovoltaic poverty alleviation, policy innovation.

\begin{abstract}
Targeted poverty alleviation develops accurate routes for poor farmers to get rich depending on characteristics of poor households and poverty-stricken areas. Photovoltaic (PV) poverty alleviation is one of the innovative targeted poverty-alleviating modes in China, in which poor household can invest in distributed PV power plant which will be later constructed in the roofs of their houses, and the power supply company will purchase all generated power from farmers at a price of 0.98yuan (\$0.14) per kwh. In this way, each poor household can earn an extra income of approximately 3,000yuan (\$435.60). To study the actual implement of PV poverty alleviation policy, our team went to Yuexi County to carry out field research, visited a total of 5 villages, 33 households. According to the investigation, we can conclude that he five villages are representative and the participants of PV project share features of low income, low educational level and lack of working ability. Based on the current situation, the power generation is very substantial, basically in line with expectations the government estimates. However, there are still many factors, like decline in PV benchmark price, affecting the long-term profits of PV poverty alleviation. While there is also innovation emerged from implement, which will lead to stable output of power generation, but extra cost. The further improvement of the innovation and the whole PV project is worth of discussion.
\end{abstract}

\section{Introduction}

Poverty is one of the most acute social problems today, and it is also a common problem faced by all countries in the world. Even in the United States, $12.7 \%$ of the population is living in poverty from an individual and family perspective. The achievements in poverty alleviation in China have attracted worldwide attention. From 1978 to 2014, the cumulative reduction of poverty population is more than 700 million, and China's rural poverty population fell from $73.5 \%$ in 1990 to $4.2 \%$ in 2014, which makes foreign media even regard China 's poverty alleviation achievements as "Chinese miracle". Ravallion (2011) considers the rapid poverty reduction in China as the contribution of market-oriented economic reform. [1] But there are still more than 70 million poor people in China waiting urgently to be out of poverty, most of these poverty-stricken areas concentrated in the middle and west of China's former revolutionary base areas and remote mountainous areas. The main features of these areas are the destruction of the ecological environment, lack of agricultural resources, inadequate infrastructure and low cultural qualities of residents. Yuexi County is one of the most impoverished counties in China with the highest poverty level and the largest poverty area. Yuexi, Anhui Province is located in the heart of the Dabie Mountains, which was listed as the first batch of state-level poverty-stricken counties in 1985. At that time, the absolute poverty population is 247,000 , accounting for $72.3 \%$ of the total population. At the end of 2010, the poverty population is still 49,000. Yuexi County was listed as one of the first batch of Photovoltaic (PV) poverty-alleviation pilot projects in Anhui Province at the end of 2014.

In order to solve the problem of poverty, China has introduced many poverty alleviation policies. In the past, the policies of rural poverty alleviation mainly included the following: meeting the dual 
goals of economic growth and poverty alleviation, adhering to the project-centered developmentoriented policy, adopting regional targeting and government-driven poverty alleviation. Carr (2008) argues that in regard of sustainable development, poverty-alleviation program that is focused on monetary aid will not show greatly improved results, unless it captures local specific causes of poverty. [2] Targeted poverty alleviation focusing on local specific causes of poverty, develops accurate routes for poor farmers to get rich depending on different situations of poor households and characteristics of poverty-stricken areas. Wang Guoyong and Xing (2015) proposed that the industrial poverty alleviation is one of the paths of targeted poverty alleviation, in which farmers can get more returns with limited labor and funds, by investing in industrial cooperation. PV poverty alleviation is one of the targeted poverty alleviation, industrial poverty alleviation. [3] Agora Moorthy and Hsu (2009) have proposed to utilize PV to improve the lives of the impoverished in India. With abundant solar energy Indian received a year, Agora Moorthy and Hsu suggested to use photovoltaic lanterns as a practical and clean energy alternative in the rural areas in India, which suffer from frequent electricity shortages. [4] PV poverty alleviation policy in China does not directly use solar energy to solve the energy problems in poor areas, but the use of photovoltaic power generation for poor households to increase income. Its main targets are the farmers who lack of collective economic income, or their collective economy is weak, lack of resources and labor. PV poverty alleviation, as a reflection of targeted poverty alleviation, can achieve an effect of one-time investment, years of benefit and stable income.

In the PV poverty alleviation policy, eligible poor households can apply to the village committee for building household-level PV power generation equipment (3kW), which is built dispersedly in the roof of farmer. After the approval, farmers can start raising funds: Yuexi County, according to the 2015 market is expected to build a 3kw PV power generation equipment at a total cost of $24,000 y u a n$ (8yuan per watt) (\$3,484.32 totally, $\$ 1.16$ per watt). The county government divides the total cost into three parts, of which the provincial subsidy, the farmer's investment, the city and county finance support each $1 / 3$, each part of 8,000 yuan $(\$ 1,161.44)$. The later actual winning price is 7.48yuan per watt ( $\$ 1.09$ per watt). The number of provincial subsidies and farmers stay the same amount of investment, while cities and counties supporting funds adjust accordingly. Since participating farmers are poor households, raising 8,000yuan $(\$ 1,161.44)$ is difficult for them, however, they can apply for small discount loans, in which the government will pay for the interest.

After the completion of fund raising, the bid-winning enterprises Sunshine Power Co., Ltd. is responsible for installing the village-level $(100 \mathrm{~kW})$ PV power plants and distributed PV power plant. The state gird is responsible for grid-connection.

The state grid takes charge of remitting the profits generated by PV power plants. The state grid will send someone to farmers to read the ammeter and check the PV power generation profits every other month. According to the power generation that is checked every two months, the national grid will directly remit the PV power generation income to farmers' account. The purchasing price is the benchmark price of PV power generation, 0.98yuan (\$0.14) per kwh, which is composed of: benchmark price of thermal power generation, which is 0.369yuan $(\$ 0.05)$ per kwh, 0.42yuan per kwh from government subsidies and 0.197yuan (\$0.03) per kwh from the new energy fund. Under the new policy adjustment in 2017, PV power generation benchmark price has been lowered, so the settlement price will also be lowered, but the power generated by the PV equipment which has been connected to the grid before the decline, will be settled at original price.

In this way, PV poverty can bring about 3,000yuan (\$435.60) annually for poor households. In addition, Yuexi County proposed to build 60kw village collective PV power plant in the poor villages, which will bring an average of 60,000yuan $(\$ 8,712.07)$ per annum for the village.

PV poverty alleviation can be described as a green method for getting-out-of poverty, which can effectively play the role of poverty alleviation, while speed up the transformation of power grids in poor areas. Meanwhile, PV poverty alleviation can not only ease the burden for the environment, but also change the way energy is used. 


\section{Method}

To investigate the actual implementation of the poverty alleviation policy in Yuexi County and the actual benefits of the poverty alleviation policy, our team went to Yuexi County in September 2016 to carry out field research, visited a total of 5 villages, 33 households. In April 2017, we conducted a tracking survey, and through the two surveys, we are able get a lot of first-hand data.

The five villages we interviewed were uniformly distributed inside the Yuexi. They were the first pilots of PV poverty alleviation policy, and each of them was representative. Through the investigation of 33 households, our team received 30 valid samples, involving 153 rural population.

$71 \%$ of the households who participated PV project in Yuexi have an annual household income between 10,000 and 40,000yuan $(\$ 1,452.01-5,808.04)$ range, with an average of about 20,000$30,000 y u a n$ (\$2,904.02-4,356.03). The income per capita is mostly less than 10,000yuan (\$1,452.01). The households participating PV project are all filing riser, of which $20 \%$ the family belongs to household enjoying the minimum living guarantee. The majority of the income is wage income. The other comes from small-scale farming, like tea, silkworm, medicinal herbs and other agricultural products. $88 \%$ of the respondents were over 40 years old, and were unable to leave their home because of incompetency Only some of them were able to work, while other young people with good working ability were basically migrant workers. As a result, farm workers are basically left-behind elderly or women or poor working people. Therefore, the agricultural income is limited, and the average annual agricultural income per household is about 2,000-3,000yuan (\$290.40435.60). To summarize, the PV policy is implemented in poor households, no other individual groups to benefit from the policy.

The general education level of the villagers is low. 64\% of surveyed family members, whose education level was primary school and junior high school, and mostly school dropouts. $13 \%$ of the surveyed family members had never received education. The remaining $23 \%$ of the family members are college degree, working away from home all year round.

Table1 shows the situations of the five villages, which have different conditions, including: the scale of the five villages, the per capita income, the poverty alleviation projects in each village, and the scale of village-level PV power plant. Due to their different geographical locations, time and installed capacity of photovoltaic power plants, the power generation of village-level PV power plant differs from 50,000kwh to 100,000kwh.

Table 1 the basic situation of 5 villages

\begin{tabular}{|c|c|c|c|c|c|}
\hline Name of village & Dushan & Tiantai & Siqiao & Lianhua & Xinxu \\
\hline Total population & 2661 & 930 & 3401 & 3001 & 2643 \\
\hline Income per capita (yuan) & $\begin{array}{c}6,000 \\
(\$ 871)\end{array}$ & $\begin{array}{c}7,500 \\
(\$ 1,089)\end{array}$ & $\begin{array}{c}9,500 \\
(\$ 1,379)\end{array}$ & $\begin{array}{c}7,000 \\
(\$ 1,016)\end{array}$ & $\begin{array}{c}8000 \\
(\$ 1,16)\end{array}$ \\
\hline $\begin{array}{c}\text { Installed capacity of village-level } \\
\text { plant (kw) }\end{array}$ & 100 & 100 & 120 & 60 & 60 \\
\hline $\begin{array}{c}\text { Grid-connected time } \\
\text { Cumulative generating capacity } \\
(\mathrm{kwh})\end{array}$ & 2015.10 & 2015.10 & 2015.10 & 2016.1 & 2015.10 \\
\hline
\end{tabular}

\section{Result}

According to Table2, government estimates the output of $3 \mathrm{~kW}$ distributed PV power plant. Within 25 years, 3KW PV power generation equipment will generate power of $71417.21 \mathrm{kwh}$, with an average annual about $2856.79 \mathrm{kwh}$. According to the $0.98 y u a n(\$ 0.14)$ per $\mathrm{kwh}$, the poor households will receive about 69,989yuan (\$10162.48) of nominal income in 25 years, with an average annual income of 2,800yuan (\$406.56). 
Table 2 Expected generation capacity

\begin{tabular}{|c|c|c|c|}
\hline Year & Annual attenuation rate(\%) & Annual Generation Capacity(kwh) & Cumulative generating capacity(kwh) \\
\hline 1 & 2.5 & 3126.01 & 3126.01 \\
\hline 2 & 0.7 & 3103.56 & 6229.57 \\
\hline 3 & 0.7 & 3081.12 & 9310.69 \\
\hline 4 & 0.7 & 3058.68 & 12369.37 \\
\hline 5 & 0.7 & 3036.23 & 15405.60 \\
\hline 6 & 0.7 & 3013.79 & 18419.39 \\
\hline 7 & 0.7 & 2991.35 & 21410.74 \\
\hline 8 & 0.7 & 2968.90 & 24379.64 \\
\hline 9 & 0.7 & 2946.46 & 27326.10 \\
\hline 10 & 0.7 & 2924.02 & 30250.12 \\
\hline 11 & 0.7 & 2901.58 & 33151.69 \\
\hline 12 & 0.7 & 2879.13 & 36030.83 \\
\hline 13 & 0.7 & 2856.69 & 38887.51 \\
\hline 14 & 0.7 & 2834.25 & 41721.76 \\
\hline 15 & 0.7 & 2811.80 & 44533.56 \\
\hline 16 & 0.7 & 2789.36 & 47322.92 \\
\hline 17 & 0.7 & 2766.92 & 50089.84 \\
\hline 18 & 0.7 & 2744.47 & 52834.31 \\
\hline 19 & 0.7 & 2722.03 & 55556.34 \\
\hline 20 & 0.7 & 2699.59 & 58255.93 \\
\hline 21 & 0.7 & 2677.15 & 60933.07 \\
\hline 22 & 0.7 & 2654.70 & 63587.77 \\
\hline 23 & 0.7 & 2632.26 & 66220.03 \\
\hline 24 & 0.7 & 2609.82 & 28829.84 \\
\hline 25 & 0.7 & 2587.37 & 31417.21 \\
\hline
\end{tabular}

We found that most of the PV power plants in poor household in Yuexi have been installed less than a year. Survey data show that, in the random sampling of 151 households participating PV project, the average power generation in two months is of 262kwh, in June and July 2016. If we use this as a monthly average generating capacity, we can derive that the electricity generating capacity is $3,144 \mathrm{kwh}$ per household in the first year, with a total generating income of 3,081.12yuan (\$447.38), higher than expected. In the follow-up survey in 2017, with the help of Yuexi National Grid, we obtained data for 2074 households in February and March 2017. The average output in two months is $480.20 \mathrm{kwh}$ per household, resulting in income of 470.53yuan (\$68.32).

Based on the current situation, the power generation is very substantial, basically in line with expectations. However, we still notice that 3,000yuan (\$435.60) per household per year can increase the household income by around $10 \%$, which is not enough to be the primary means of poverty alleviation.

\section{Conclusion}

\subsection{Benefits of PV poverty alleviation}

The overall implementation of PV poverty alleviation is in good condition. According to our survey, there are no other individual groups to benefit from the policy. Compared to other modes of poverty alleviation, PV poverty alleviation is more suitable for the impoverished population in Yuexi, whose main population does not have normal working ability and required education level, simply other modes require more contribution of labor participation. The revenue of distributed PV power plant, according to the current information, can reach 3,000yuan (\$435.60) per household standards. However, in the future, there are still many factors that may affect the stability of earnings.

From the introduction of the NDRC 2017 PV benchmark tariff policy, the future purchase price of PV power is on a downward trend. So, if we want to maintain the income of farmers, the 
government has to allocate some additional funds for subsidies. Otherwise, the income of farmers will decline accordingly, and then their willingness to participate will decline. According to the survey, more than $20 \%$ of the farmers said that the government has promised there will be annual income of 2,000-3,000yuan from PV poverty alleviation. Therefore, lower income than expected may temper the enthusiasm of poor farmers.

In addition, due to the low educational level of the villagers, the maintenance of PV equipment is also one of the hidden factors that can lead to the decrease in income. The survey found that the educational level of 93\% of respondents is junior high school and below, so their awareness of PV equipment maintenance requirement was relatively weak. Lack of maintenance will lead to lower PV revenues.

Natural factors will also affect the stability of earnings. Comparison between 2017 and 2016 power generation data shows that the total revenue (2,823.18yuan, \$409.93) in 2017 is lower than the total revenue (3,081.12yuan, \$447.38) in 2016, this is because the data is obtained from different season and climatic distinction in different season will affect the output. Furthermore, illumination is also a factor. Yuexi County is located in mountainous area, so the lack of sun light and the debris flow are very likely to happen, which will significantly reduce the profits. So as for Yuexi, natural factors are the main factors that prevent PV power plant generating greater and stable benefit.

\subsection{Policy Innovation}

In the investigation, we found that there are many innovative ideas emerged in the process of actual execution. According to the policy document issued by the state, the only way for farmers to participate in the "PV poverty alleviation" is to install their own distributed PV equipment on the roof of each poor family, and connect the equipment to the grid separately. However, Dushan village in Yuexi centralized installation of distributed PV equipment experimentally, and now this mode is extended to the countywide.

Later the National grid and Poverty Alleviation Office began to appeal: centralize all the construction of distributed PV devices and the income of the power generation will be equally distributed to the participating farmers. This policy improvement is mainly due to the benefits of centralized construction, which makes the income more stable and fair, because it can avoid the discrepancy of different household (such as housing lighting conditions difference). Furthermore, it is more convenient for specialized personnel to take charge of the maintenance of the centralizeconstructed PV power plant, which can prolong service life of equipment and ensure the gain from PV power generation. The State Grid says that the distributed PV power plant construction will cause a series of problems, like the over voltage, tidal current change and difficulties in line rectification, which will affect not only other residential electricity consumption but also the efficiency of power grid connection. Centralized construction can address these problems and lower the requirements for the transmission line.

However, centralized construction will cause additional manpower cost, rent cost and cost of transmission line. After the centralized construction, village committee needs to arrange specialized person to supervise the PV equipment, which will lead to the increase of labor cost. Centralized construction needs the power supply company to build a specialized transmission line, resulting in the additional cost of line rectification. Meanwhile, the government needs to expropriate wasteland or agricultural land in the village to build the centralized PV power plant. The cost of land acquisition should be deducted from the income generated from the power generation. The Renting is usually 600yuan (\$87.12) per mu (667 square meter) per year, or is the price of rice that can be produced in the expropriated areas, while the usual production per mu (667 square meter) is 650 pounds. $60 \mathrm{kw}$ PV power plant covers an area of $1.5 \mathrm{mu}$ (1000 square meter), so the rent is 900yuan (\$130.72) per years, as for 20 years, a total of 18,000yuan (\$2614.38), 10,817.89 yuan (\$1571.23) after discounting. Moreover, centralization will also affect the enthusiasm of participating farmers, according to the survey, because farmers can intuitively see the growth of profits, by reading the ammeter, if the PV power plants are constructed on their own roofs. 
In conclusion, considering how to ensure the benefits of PV poverty alleviation policy, and how to carry on the policy innovation, there are still many issues worth of further research and discussion.

\section{References}

[1]. Martine Ravallion, A Comparative Perspective on Poverty Reduction in Brazil, China, and India [J], The world Bank Research Observer, 2011, 26 (1), pp. 71-104.

[2]. Edward R. Carr, Rethinking Poverty Alleviation: A 'Poverties' Approach [J], Development in Practice, 2011, 18 (6), pp. 726-734.

[3]. Wang Guoyong, Xing Wei, Study on the Targeted Measures of Poverty Alleviation in China [J], Rural Economics, 2015 (9), pp. 46-50.

[4]. Govindasamy Agoramoorthy, Minna J. Hsu, Lighting the Lives of the Impoverished in India's Rural and Tribal Drylands [J], Human Ecology, 2009, 37 (4), pp. 513-517. 